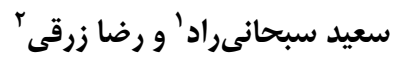

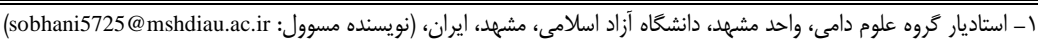

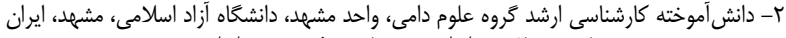

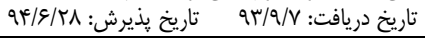

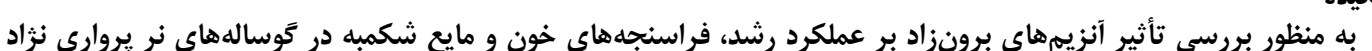

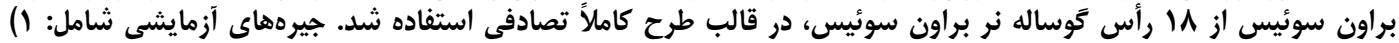

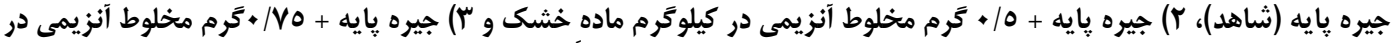

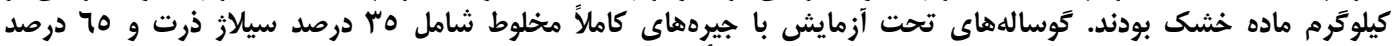

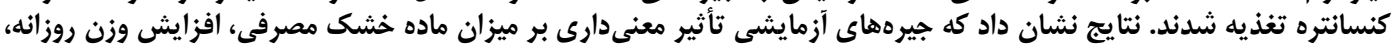

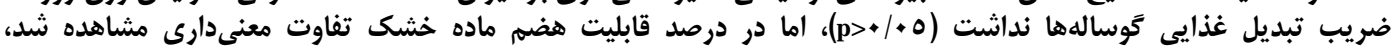

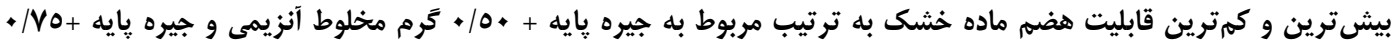

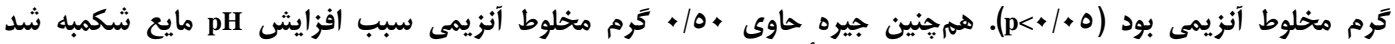

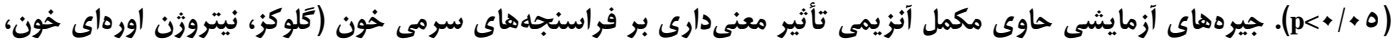

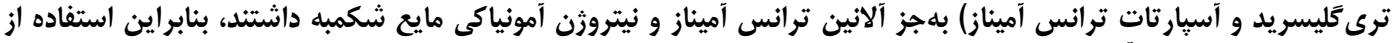

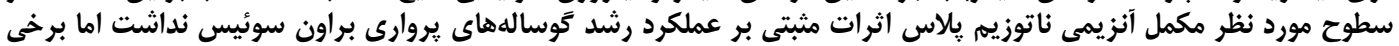

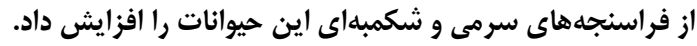

وازمهاى كليدى: مكمل آنزيمى، عملكرد رشد، متابوليتهاى خون، فراسنجههاى شكمبه، توساله يروارى

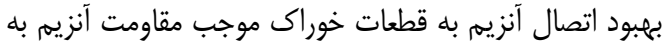

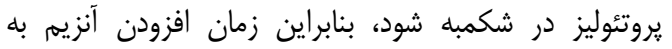

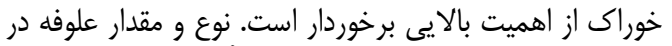

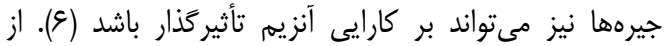

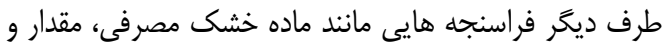

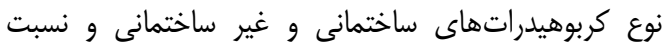

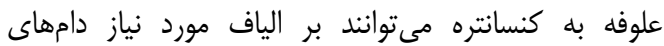

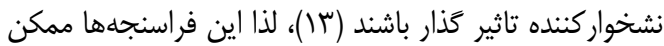

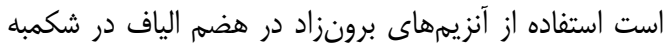

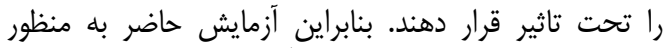

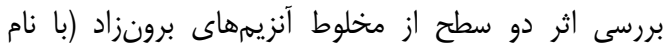

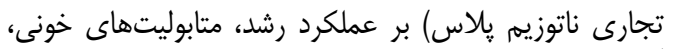

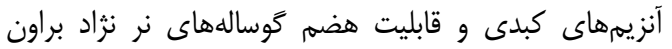

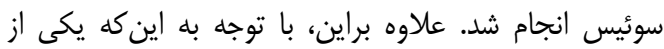

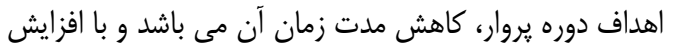

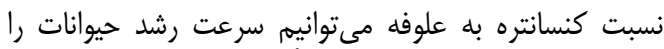
افزايش دهيه، در اين تحقيق تأثير آنزيمهاى برعائ برونزاد دران در جيرههاى كم علوفه مورد بررسى قرار ترفتي آنرئ.

\section{مواد و روشها - ماري}

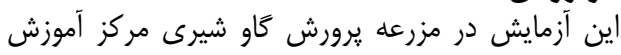

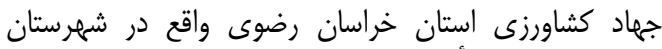

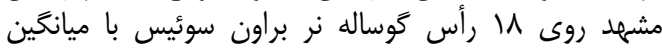

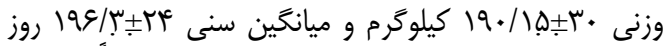
به مدت VD روز انجام شد. كوسالهها به صورت كاملاً تصادفى سئ

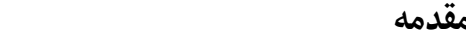

به منظور تأمين احتياجات حيوانات نشخواركننده به به ويزره

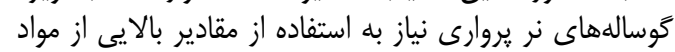

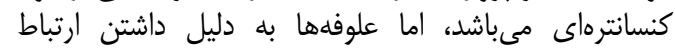

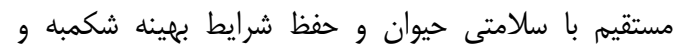

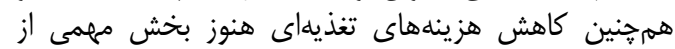

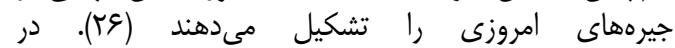

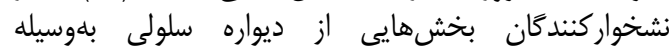

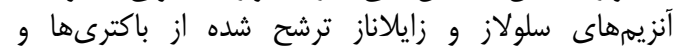

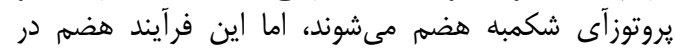

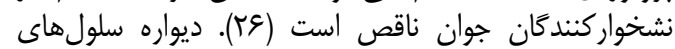

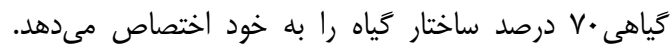

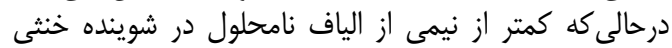

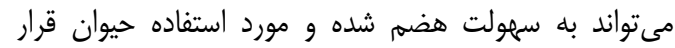

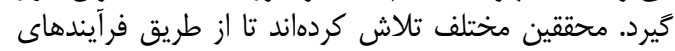

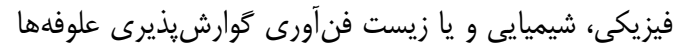

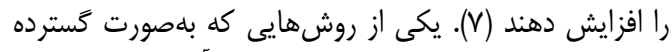

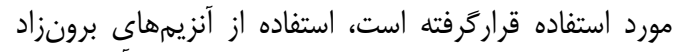

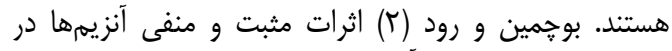

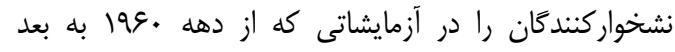

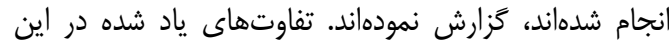

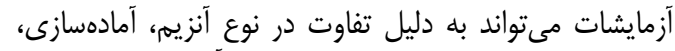

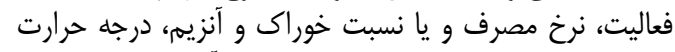

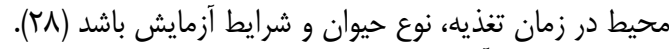

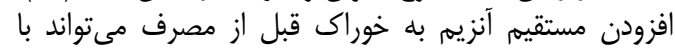


محصول كميانى بيويروتن استراليا (سلولاز، زايلاناز،

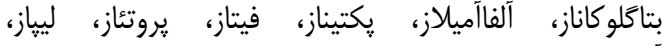

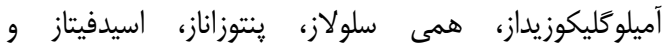

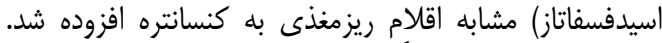

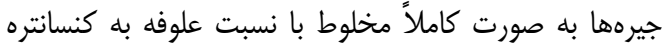

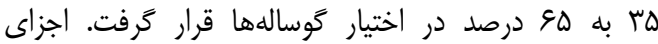

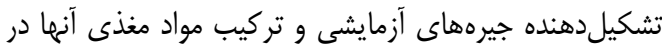
جدول ال ارايه شده است.
بر اساس وزن به سه گروه (تيمار) تقسيمبندى شدند.

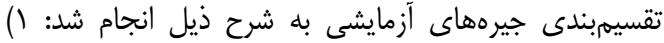

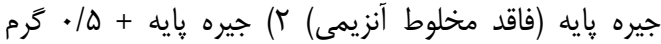

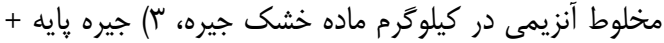

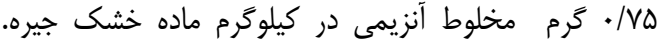

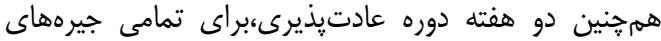

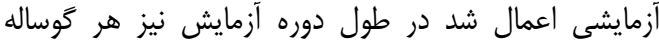

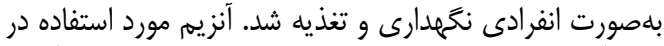

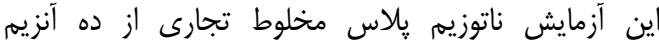

جدول ا- نسبت مواد خوراكى و تركيب شيميايى جيرههاى آزمايشى (درصد ماده خشك جيره) Table 1. The proportion of feedstuffs and the chemical composition of the experimental diets (\% of diet DM)

\begin{tabular}{|c|c|c|c|}
\hline 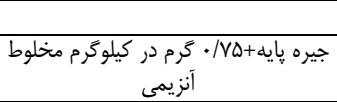 & 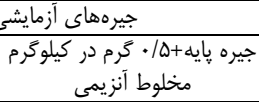 & جيره يايه & ماده خوراكى \\
\hline ro & ro & ro & سيلاز ذرت \\
\hline$r T / \cdot F$ & $\mathrm{~m} / \cdot \mathrm{F}$ & $r T / . F$ & جو \\
\hline $\mid r / \cdot r$ & $\mid r / \cdot r$ & $\mid r / \cdot r$ & سبوس \\
\hline$N / T$ & $N / T$ & $N / T$ & كنجاله تخم ينبه \\
\hline$N / A F$ & $N / A F$ & $N / A F$ & كنجاله كلزا \\
\hline$\cdot / V 1$ & $\cdot / V 1$ & $\cdot / V 1$ & كربنات كلسيم \\
\hline זr/ & r & r & اكسيد منيزيم | - كا \\
\hline .190 & .190 & .190 & اوره \\
\hline $1 / \%$ & $1 / \pi$. & $1 / \%$. & بتتونيت سديم \\
\hline זr/. & r & r & 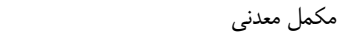 \\
\hline זr & זr/. & זr & مكمل ويتامينه \\
\hline זr & Tr & r & نمكى \\
\hline \multirow[t]{2}{*}{.$/ \cdot v$} &.$/ \cdot 0$ & . & مكمل آنزيمى \\
\hline & & & 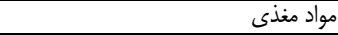 \\
\hline T/QT & $r / \Delta T$ & $r / \Delta T$ & انرزى متابوليسمى (مكاكالرى بر كيلوكرم) \\
\hline IV/QD & IV/QD & IV/QD & يروتئين خام (درصد) \\
\hline rY/99 & Mr/gG & $r r / 99$ & الياف نامحلول در شوينده خنثى (درصد) \\
\hline $\mid V / F$ & IV/F & IV/F & 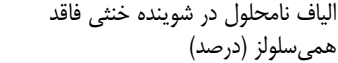 \\
\hline$r / 9 V$ & r/qV & r/qV & جربى خام (درصد) \\
\hline $9 / 90$ & $q / \varnothing \Delta$ & $q / 9 \Delta$ & 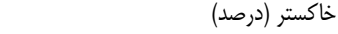 \\
\hline$\cdot(\Delta)$ & $\cdot|\Delta|$ & $\cdot|\Delta|$ & كلسيم (درصد) \\
\hline$\cdot / \Delta \Delta$ & $\cdot / \Delta \Delta$ & $\cdot / \Delta \Delta$ & فسفر (درصد) \\
\hline
\end{tabular}

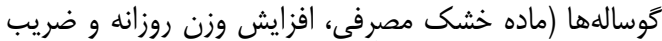

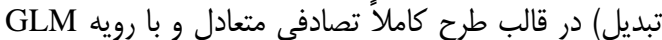

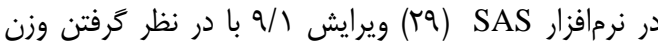

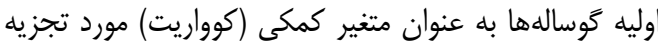

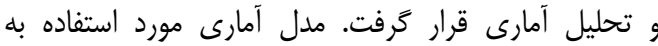

$\mathrm{Y}_{\mathrm{ij}}=\mu+\mathrm{T}_{\mathrm{i}}+\mathrm{e}_{\mathrm{ij}}$

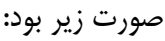

در اين مدل؛ YIJ تجا TI

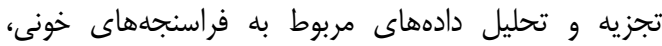

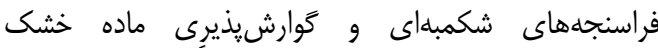

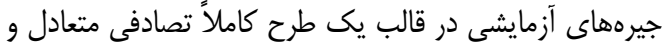

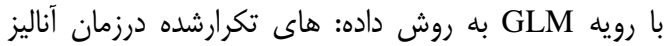
شدند. در نرمافزار SAS نسخه

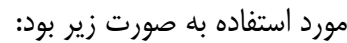
$\mathrm{Y}_{\mathrm{ijkm}}=+\mathrm{T}_{\mathrm{i}}+\mathrm{C}_{(\mathrm{i}) \mathrm{j}}+\mathrm{P}_{\mathrm{k}}+(\mathrm{T} \times \mathrm{P})_{\mathrm{ik}}+\varepsilon_{\mathrm{m}(\mathrm{ijk})}$

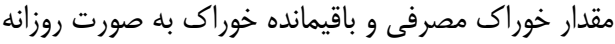

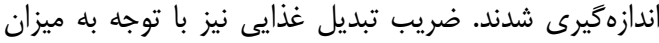

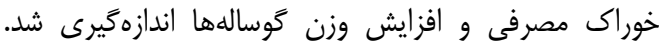

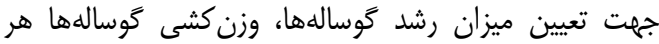

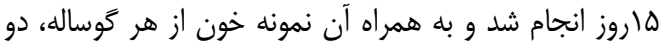

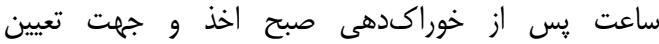

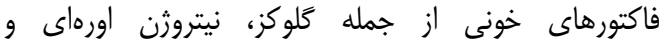

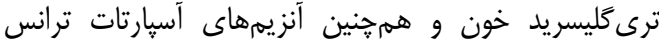

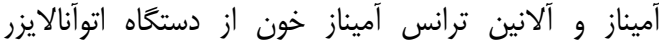

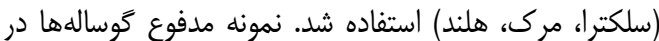

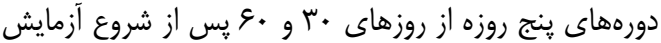

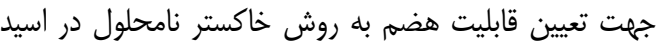

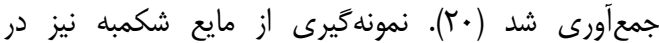

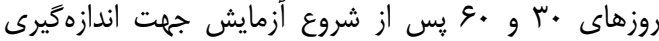

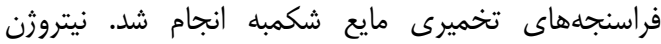

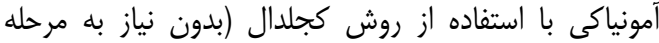

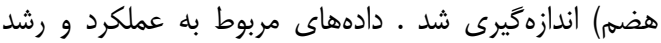


افزايش وزن روزانه كاوهاى بروارى را افزايش داد. از طرفى إنى

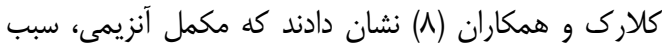

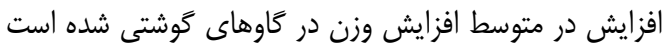

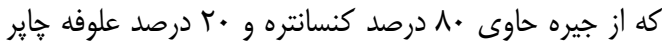

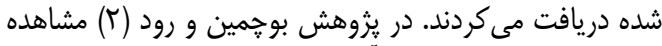

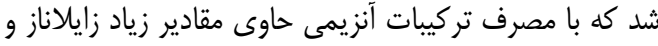

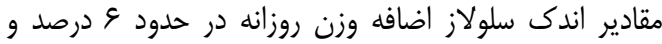

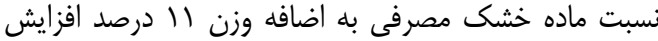

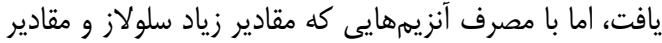

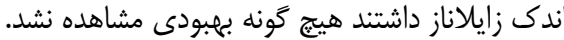

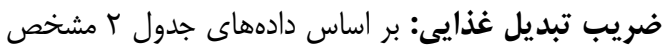

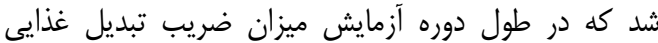

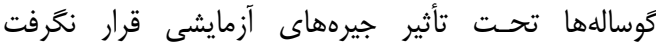

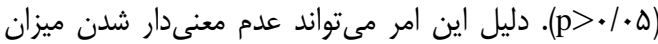

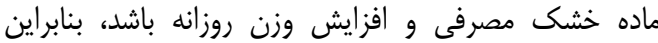

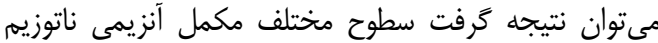

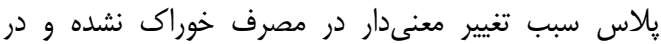

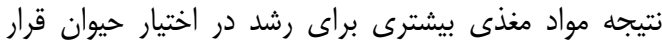

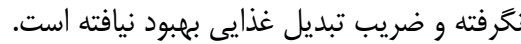

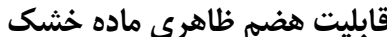

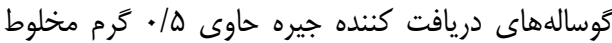

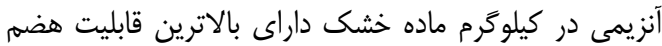

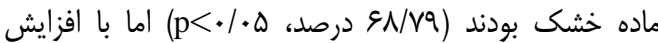

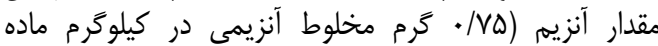

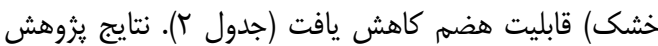

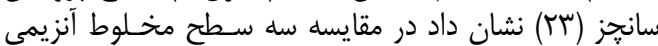

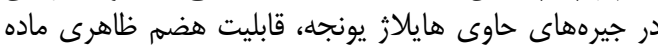

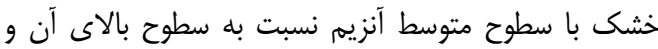

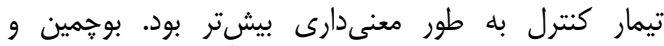

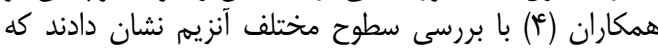

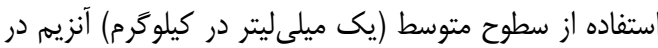

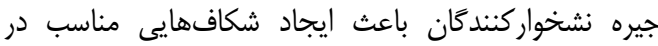

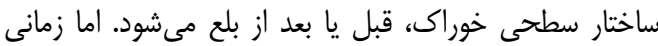

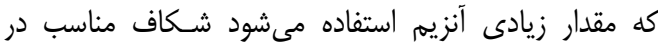

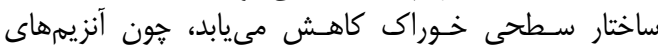

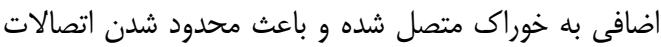

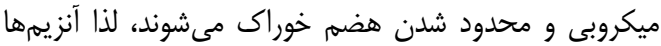

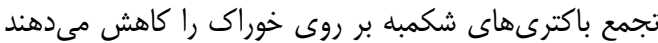

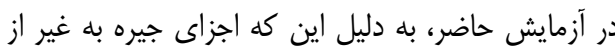

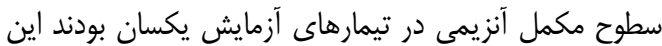

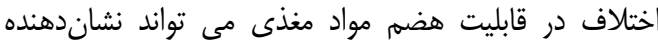

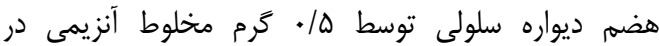

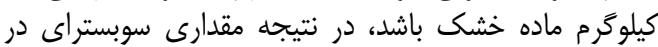

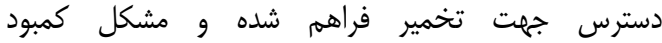
كربوهيدرات محلول به نوعى مرتفع مى شود (Tها (Tه).
در اين مدل، Y Y Y متغير وابسته، : ميانكين كل متغير وابسته، Th

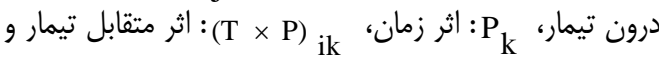

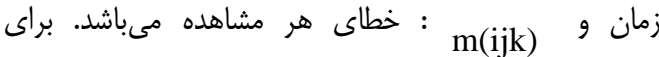
مقايسه ميانگين تيمارها از ميانكين حداقل ماندان مربعات و آزمون

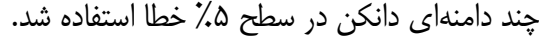

نتايج و بحث

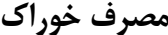

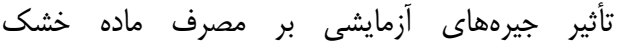

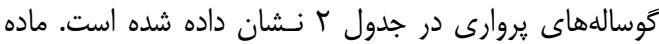

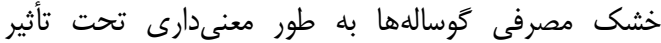

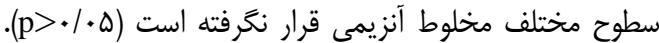

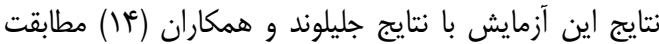

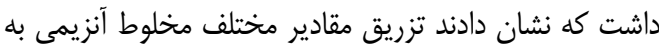

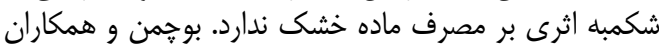

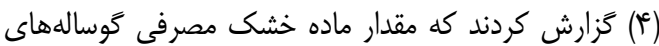

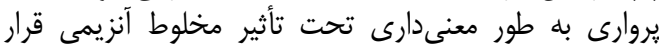

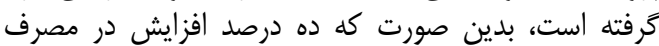

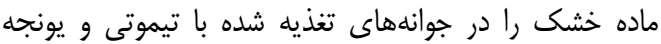

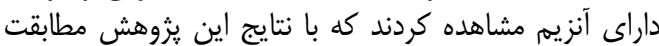

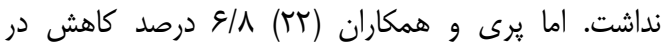

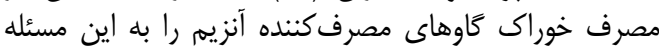

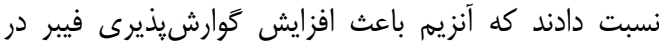

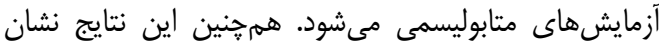

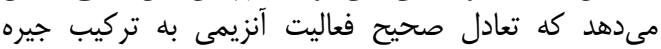

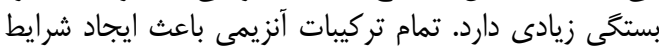

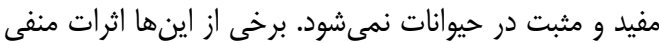

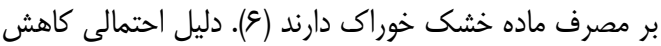

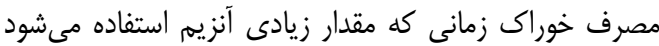

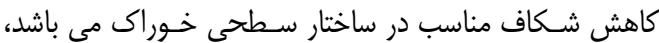

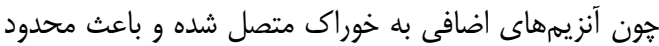

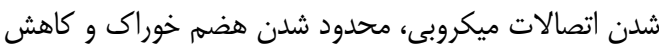

مصرف خوراك مى شوند (19). افزايش وزن روزانه

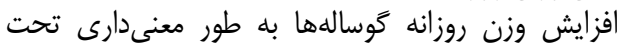

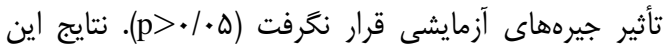

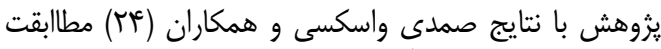

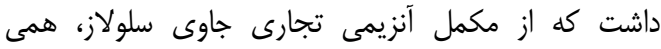

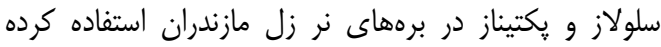

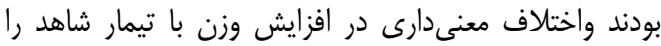

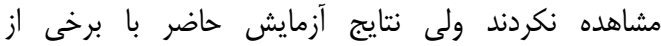

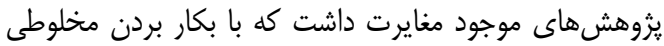

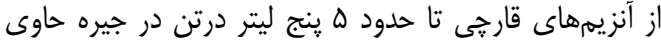

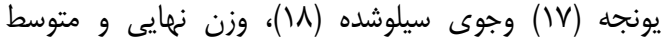


جدول r- اثر افزودن مخلوط آنزيمى بر عملكرد و رشد گوساله هاى نر براوون سوئيس

\begin{tabular}{|c|c|c|c|c|c|}
\hline \multirow[b]{2}{*}{ احتمال معنىدارى } & \multirow[b]{2}{*}{ SEM } & \multicolumn{3}{|c|}{ جيرههاى آزمايشى } & \\
\hline & & كيلوَّر بايه+مخلوط آنزيمى در & كيلو كرم مخخلوط إنزيمى در & جيره هايه & \\
\hline$\cdot / F Q$ & $\cdot / T F$ & $8 / \mathrm{V}$ & $V / T S$ & $\mathrm{~V} / \cdot \cdot$ & ماده خشك مصرفى (كيلوكرم) \\
\hline$\cdot|\Lambda|$ & $\cdot 1 \cdot 1$ & $1 / 41$ & $1 / \% \Delta$ & $1 / 01$ & افزايش وزن روزانه (كيلوكَّم) \\
\hline זr/. & . & $r / r r$ & r/q9 & f/\& & ضريب تبديل غذايى \\
\hline .1 .4 & $1 / 49$ & $b_{G} \times / T$ & ${ }^{a} 9 N / V q$ & ${ }^{\mathrm{b}} 94 / 9 \mathrm{q}$ & قابليت هضم ماده خشك (درصد) \\
\hline
\end{tabular}

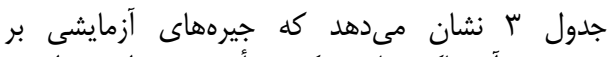

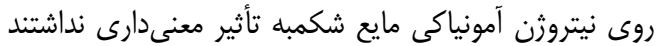

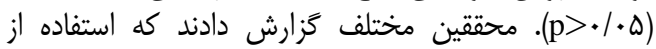

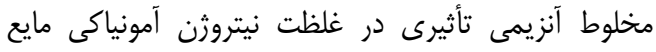

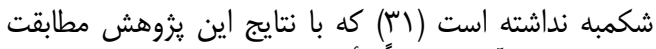

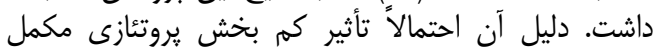

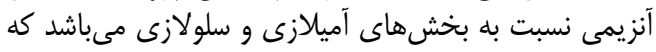

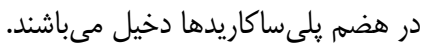

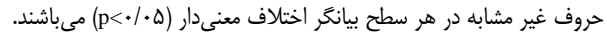

فراسنجههاى مايع شكمبه

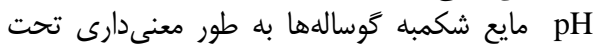

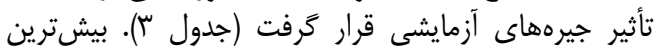

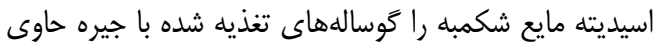

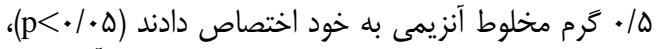

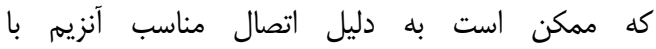
كربوهيدراتها و در نتيجه آزاد شدن و هضم يلى إنساكاريدها باشد.

جدول بـ- اثر افزودن مخلوط آنزيمى بر فراسنحههاي مايع شكمبه گوسالههاي نر براوون سوئيس Table 3. Effect of mixed enzyme on rumen fluid parameters of Brown Swiss male calves

\begin{tabular}{|c|c|c|c|c|c|}
\hline \multirow[b]{2}{*}{ احتمال معنىدارى } & \multirow[b]{2}{*}{ SEM } & \multicolumn{3}{|c|}{ جيرههاى آزمايشى } & \\
\hline & & كيلوَّرم مخايهلوط آنزيمى در & 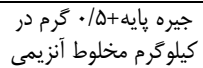 & جيره پِايه & \\
\hline$\cdot / T \Delta$ & $1 / \Delta \Lambda$ & $1 F / 1$. & ع & $\mid r / 19$ & (ميلى كرم نيترورن دسى ليتياكى) \\
\hline $.1 \cdot 4$ & $\cdot / 11$ & b/l & $8 / \Delta \cdot{ }^{\mathrm{a}}$ & $9 / \cdot 0^{\circ}$ & مH مايع شكمبه \\
\hline
\end{tabular}

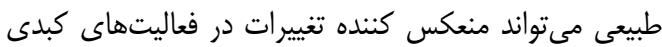

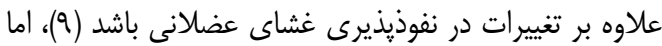

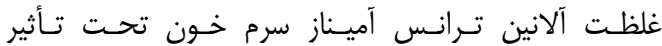

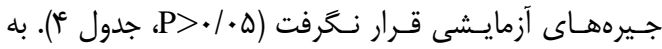

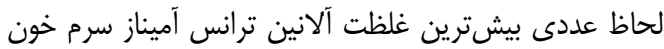

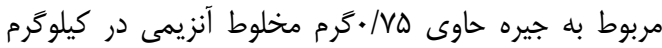

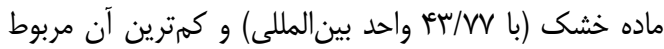

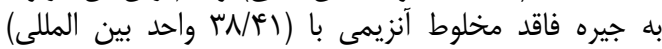

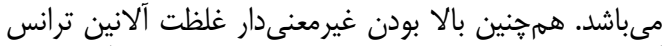

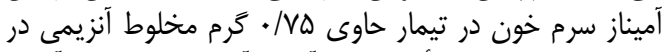

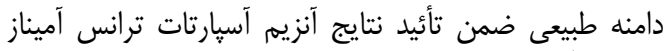

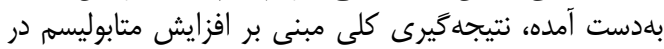
سلولهاى كبدى را نيز تأئيد مىنمايد.
فراسنجلهاى سرمى خونى

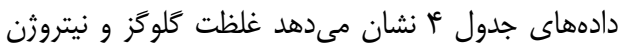

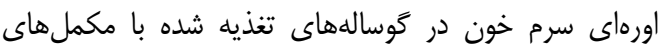

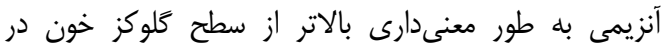

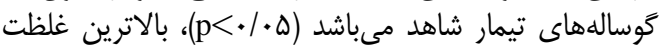

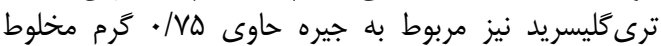

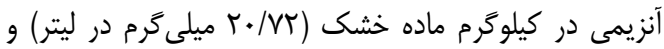

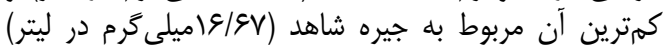

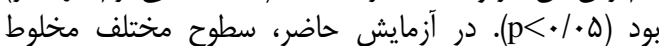

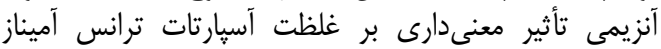

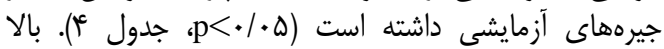

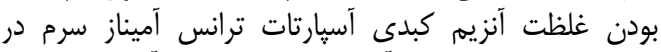
جيرههاى حاوى مخلوط آنزيمى و قرار داشتن آن در آنيار محدوده 
جدول عا- فراسنجههاى سرم خون گوسالههاى تغذيه شده با جيرههاى آزمايشى Table 4. Blood serum parameters of calves fed experimental diets

\begin{tabular}{|c|c|c|c|c|c|}
\hline \multirow[b]{2}{*}{ احتمال معنى دارى } & \multirow[b]{2}{*}{ SEM } & \multicolumn{3}{|c|}{ جيرههاى آزمايشى } & \\
\hline & & 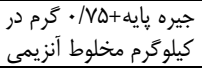 & 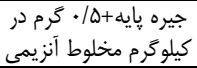 & جيره پِايه & \\
\hline.$/ \cdot 1$ & $1 / \Delta T$ & $v q / \cdot \Delta^{a}$ & $V N / \Delta \Lambda^{a}$ & $V T / T \mathcal{G}^{D}$ & كلوكز (ميلى گرم در دسىليتر) \\
\hline $.1 \ldots 1$ &.$/ 4 \mathrm{~V}$ & $\mid r / \Delta \Delta^{\mathrm{a}}$ & $\mid r / \& \Lambda^{\mathrm{a}}$ & $N / N \mathcal{F}^{D}$ & نيترورن اورهاى (ميلى گرم در دس \\
\hline $.1 . .9$ & $\cdot / \Lambda$ & $r \cdot / / r^{\mathrm{a}}$ & $|\varepsilon / 9|^{D}$ & $19 / 9 V^{\circ}$ & 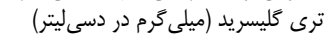 \\
\hline.$/ .1$ & $\Delta / r \Delta$ & $1 \% q / q v^{a}$ & $\mid r V / r \gamma^{\mathrm{ab}}$ & ||$F /\left.9\right|^{D}$ & آسبارتات ترانس آميني \\
\hline . & $T / V \cdot r$ & $\mathrm{r} / \mathrm{WV}$ & FT/VG & $|N / F|$ & آلانينترانس آميناز (واحد بينالمللى) \\
\hline
\end{tabular}

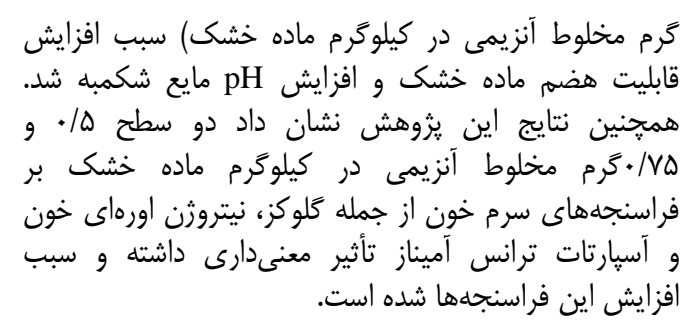

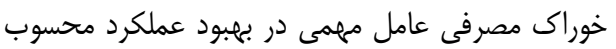

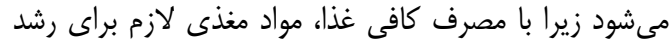

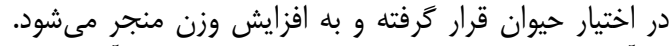

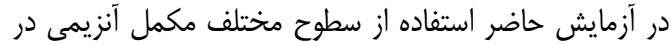

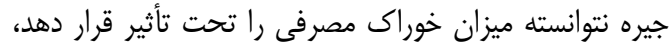

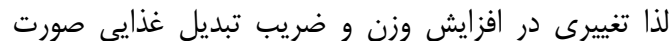

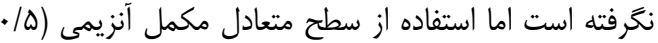

1. Balci, F., S. Dikmen, H. Gencoglu, A. Orman, I.I. Tukmen and H. Biricilk. 2007. The effect of fibrolytic exogenous enzyme on fattening performance of steers. Bulgarian Journal of Veterinary Medicine, 10, 2: 113-118.

2. Beauchemin, K.A. and L.M. Rode. 1996. Use of feed enzymes in ruminant nutrition. Animal science research and development: meeting future challenges. 103-131 pp., Ministry of Supply and Services Canada, Ottawwa.

3. Beauchemin, K.A., L.M. Rode and V.J.H. Sewalt. 1995. Fibrolytic enzymes increase fiber digestibility and growth rate of steers fed dry forages. Canadian Journal of Animal Science, 75: 641644.

4. Beauchemin, K.A., L.M. Rode, M. Maekaw, D. Morgavi and R. Kampen. 2000. Evaluation of a nonstarch polysacchridase feed enzyme in dairy cow diets. Journal of Dairy Science, 83: 453-553.

5. Beauchemin, K.A., S.D.M. Jones, L.M. Rode and V.J.H Sewalt. 1997. Effects of fibrolytic enzyme in corn or barley diets on performance and carcass characteristic of feedlot cattle. Canadian Journal of Animal Science, 77: 645-653.

6. Beauchemin, K.A., W.Z. Yang and L.M. Rode. 1999. Effects of grain source and enzyme additive or grain source on site and extent of nutrient digestion in dairy cows. Journal of Dairy Science. 82: 378390.

7. Bedford, M.R. and G.G. Partridge. 2001. Enzymes in farm animal nutrition. finn feeds marlborough wiltshire. CABI Publishing, 397 pp.

8. Clark, J.D., I.A. Dyer and J.A. Templeton. 1961. Some nutrition and physiological effects of enzymes for fattening cattle. Journal of Animal Science. 20 (Suppl. 1). 928 pp.

9. Coles, E.H. 1986. Veterinary clinical pathology. $4^{\text {th }}$ Ed. W.B. $486-488$ pp. Saunders Company, Philadelphia, PA, USA.

10. Colombatto, D., D.P. Morgavi, A.F. Furtado and K.A. Beauchemin. 2002. Screening of fibrolytic enzymes as additives for ruminant diets: relationship between enzyme activities and the in vitro degradation of enzyme-treated forages. British Society Animal Science. Annu. Mtg. 210 pp. Penicuik, 210 pp. U.K.

11. Eun, J.S. and K.A. Beauchemin. 2005. Effects of proteolytic feed enzyme on intake, digestion, ruminal fermentation, and milk production. Journal of Dairy Science, 88: 2140-2153.

12. Feng, P., C. W. Hunt, G.T. Pritchard and W.E. Julien. 1996. Effect of enzyme preparation on in situ and in vitro digestive characteristics of mature cool-season grass forage in beef steers. Journal of Animal Science, 74: 1349-1357.

13. Golchin Gelehdooni, S., A. Teimouri Yansari and H. Taghavi Kargan. 2013. The effects of alfalfa particle size and processed canola meal on physiocochemical properties of ration in Zel sheep. Research on Animal Production, 4: 47-61 (In Persian). 
14. Hristov, A.N., T.A. McAllister, K.J. Cheng. 2000. Intraluminal supplementation With increasing levelofexogenous polysaccharide- degrading enzymes: effects on nutrient digestion in cattle fed barlay grain diets. Journal of Animal Science, 78: 477-487.

15. Jalilvand, Gh., A.A. Naserian and R.Valizadeh. 2010. Effect of ruminal infusion of different levels of an enzymatic mixture on nutrients digestibility of sheep. The $4^{\text {th }}$ Congress on Animal Science, Tehran. Iran (In Persian).

16. Lewis, G.E., C.W. Hint, W.K. Sanchez, R. Treacher, G.T. Prichard and P. Feng. 1996. Effect of direct-fed fibrolytic enzymes on the digestive characteristics of a forage-based dite fed to beef steers. Journal of Animal Science, 74: 3020-3028.

17. Mathlouthi, N., L. Saulnier, B. Quemener and M. Larbier. 2002. Xylanase, B-glucanase and other side enzymatic activities have greater effects on viscosity of several feed stuffs than Xylanase, B-glucanase use along or in combination. Journal of Agricultural and food Chemistry, 50: 5121-5127.

18. McAllister, T.A., S.J. Oosting, J.D. Popp, Z. Mir, L.J. Yank, A.N. Hristov, R.J. Treacher and K.J. Cheng. 1999. Effects of exogenous enzymes on digestibility of barley silage and growth performance of feedlot cattle. Canadian Journal of Animal Science, 79: 353-360.

19. Michal, J.J., K.A. Johnson, R.J. Treacher, C.T. Gaskins and O. Sears. 1996. The impact of direct fed fibrolytic enzymes on the growth rate and feed efficiency of growing beef steers and heifers. Journal of Dairy Science, 74 (Suppl. 1), 296 pp.

20. Morgavi, D.P., C.J. Newbold, D.E. Beever and R.J. Wallace. 2000. Stability and stabilization of potential feed additiveenzymes in rumenfluid. Enzymeand Microbial Technology, 26: 171-177.

21. Nakamura, T., T.J. Klopfenstein, R.A. Britton. I994. Evaluation of acid detergent insoluble nitrogen as an indicate of protein quality in non forage proteins. Journal of Animal Science, 72: 1043.

22. Nsereko, V.L., K.A. Beauchemin, D.P. Morgavi, L.M. Rode, A.F. Furtado, T.A. McAllistr, A.D. Iwaasa, W.Z. Yang and Y. Wang. 2002. Effect of a fibrolytic enzymes preparation from Trichoderma longibrachiatum on the rumen microbial population of Dairy cows. Canadian Journal of Microbiology, 48: 14-20.

23. Perry, T.W., E.D. Purkhiser and W.M. Beeson. 1966. Effect of supplemental enzymes on nitrogen balance, digestibility of energy and nutrients and and on growth and feed efficiency of cattle. Journal of Animal Science, 25: 760-764.

24. Samadi Vaskasi, H., A. Teimouri Yansari, S. Golchin Gelehdooni and H. Taghavi Kargan. 2014. Effect of Iranian clover silage processing with easily degradable carbohydrates and Enzyme on Intake, digestibility, chewing behavior and body weight gain in Zell Sheep. Research on Animal Production, 5: 69-82 (In Persian).

25. Sanchez, W.K., C.W. Hunt, M.A. Guy, G.T. Pritchard, B.I. Swanson, T.B. Warner and J.M. Higgins.1996. Effect of fibrolytic enzymes on lactational performance of dairy cows. Journal of Dairy Science 79, Suppl. 1, 183 pp.

26. SAS User's Guide: Statistics, Version $9.1^{\text {th }}$ edition. 1989. SAS Inst., Inc., Cary, NC.

27. Sheperd, A.C., M. Maslanka, D. Quinn and L. Kung, 2007. Additives containing bacteria and enzymes for alfalfa silage. Journal of Dairy Science, 78: 565-572.

28. Soufi Siavash, R. and Jan H. Mohammadi. 2004. Animal nutrition. McDonald. $5^{\text {th }}$ edition.2nd printing. Tehran (In Persian).

29. Sutton, J.D., R.H. Phipps, D.E. Beever, D.J. Humphries, G.F. Hartnell and J.L. Vicinh. 2003. Effect of method of application of fibrolytic enzyme production digestive processes and milk production in Holstien Friesian cows. Journal of Dairy Science, 86: 546-556.

30. Tiffany, M.E. and J.W. Spears. 2005. Differential vesponses to dietary cobalt in finishing steers fed cornvs. Barler-base diets. Journal of Animal Science, 83: 2580-2589.

31. Yang, W.Z., K.A. Beauchemin and L.M. Rode. 1999. Effect of enzyme feed additives on extent of digestion and milk production of lactating dairy cows. Journal of Dairy Science, 82: 391-403. 


\title{
The Effect of Exogenous Enzymes on Growth Performance, Some Blood and Rumen Parameters of Brown Swiss Fattening Male Bulls
}

\author{
Saeid Sobhanirad ${ }^{1}$ and Reza Zarghi $^{2}$ \\ 1- Assistant Professor of Department of Animal Science, Mashhad Branch, Islamic Azad University, Mashhad, Iran, \\ (Corresponding Author: sobhani5725@mshdiau.ac.ir) \\ 2- Graduated M.Sc. Student, of Department of Animal Science, Mashhad Branch, Islamic Azad \\ University, Mashhad, Iran \\ Received: November 28, $2014 \quad$ Accepted: September 19, 2015
}

\begin{abstract}
In order to investigating the effect of exogenous enzymes on growth performance, blood and rumen parametes, 18 Brown Swiss male bulls were used in an balanced completely randomized design. The experimental diets were: 1) basal diet (control), 2) basal diet containing $0.50 \mathrm{~g}$ enzymatic mixture $/ \mathrm{kg}$ DM of diet and 3 ) basal diet containing $0.75 \mathrm{~g}$ enzymatic mixture $/ \mathrm{kg} \mathrm{DM}$ of diet. The bulls were fed total mixture ration (35 percent corn silage and 65 percent concentrate). Results showed that the experimental diets had no significant effect on dry matter intake, average daily gain and feed conversion ratio $(\mathrm{P}>0.05)$, but significant differences were observed in dry matter digestibility of diets $(\mathrm{P}<0.05)$, as highest and lowest of dry matter digestibility were related to diet containing $0.50 \mathrm{~g}$ enzymatic mixture $/ \mathrm{kg} \mathrm{DM}$ and $0.75 \mathrm{~g}$ enzymatic mixture/kg DM, respectively. Rumen liquid $\mathrm{pH}$ of the calves was significantly affected by the experimental diets $(\mathrm{P}<0.05)$. Calves fed with diet containing $0.50 \mathrm{~g}$ enzymatic mixture / kg DM had the highest rumen liquid $\mathrm{pH}$. Rumen liquid NH3-N wasn't significantly affected by the experimental diets $(\mathrm{P}>0.05)$. The experimental diets containing enzymatic supplement had significantly affect on blood metabolites (glucose, blood urea nitrogen, triglyceride and aspartate transaminase) except for alanine transaminase and rumen liquid NH3N. Therefore, using of enzymatic supplement did not has positive effects on growing performance in brown Swiss fattening bulls, but enzymatic supplement increased some of serum blood and rumen parameters.
\end{abstract}

Keywords: Blood Parameters, Enzyme Mixture, Fattening Bull, Growth Performance, Rumen Parameters 